\title{
Palestina: memórias e aprendizados de uma viajante
}

\author{
Palestine: memories and learnings of a traveler
}

Palestina: memorias y aprendizajes de una viajera

\author{
Ana Maria Marques ${ }^{1}$
}

\begin{abstract}
Resumo: $\mathrm{O}$ artigo parte de uma experiência de viagem com um grupo de brasileiros à Palestina em 2019. O tour guiado por palestinos e uma brasileira que lá viveu desvendou histórias pouco e mal conhecidas pelo ocidente, devido às notícias que chegam no Brasil, especialmente. A narrativa segue o percurso da viagem. As memórias, vivências, anotações e leituras posteriores da autora resultaram nesse texto que aborda: os impactos da chegada em Tel-Aviv, a violência da colonização de Israel nos territórios palestinos da Cijordânia, o questionamento sobre a suposta submissão das mulheres por meio do uso do véu, a riqueza dos sabores e algumas considerações sobre esse local sagrado para cristão, judeus e muçulmanos.
\end{abstract}

Palavras-chave: Palestina, memórias, violências, alimentação, religião.

Abstract: This article is part of a travel experience with a group of Brazilians to Palestine in 2019. The tou,r guided by Palestinians and a Brazilian woman who lived there unveiled those little and poorly stories known by the West world especially, due to the news arriving in Brazil,. The narrative follows the route of the journey. Memories, experiences, notes and subsequent readings of the author resulted in this text that makes an approach on the impacts of the arrival in Tel-Aviv, the violence of Israeli colonization in the Palestinian territories of Cisjordania, the questioning about the supposed submission of women through the use of the veil, the richness of flavors and some considerations about this sacred place for Christians, Jews and Muslims.

Keywords: Palestine, memories, violence, food, religion.

Resumen: Este artículo parte de una experiencia de viaje con un grupo de brasileros a Palestina en 2019. El recorrido, guiado por palestinos y una brasilera que vivió allí reveló historias poco y mal conocidas por Occidente debido especialmente a las noticias que llegan al Brasil. La narrativa sigue la ruta del viaje. Memorias, vivencias, anotaciones y lecturas posteriores del autor dieron como resultado este texto que aborda los impactos de la llegada a Tel-Aviv, la violencia de la colonización de Israel en los territorios palestinos de Cisjordania, el cuestionamiento sobre la supuesta sumisión de las mujeres a través del uso del velo, la riqueza de sabores y algunas consideraciones sobre este lugar sagrado para cristianos, judíos y musulmanes.

Palabras clave: Palestina, memorias, violencias, alimentación, religión.

\footnotetext{
${ }^{1}$ Doutora em História. Professora Associada do Departamento de História da Universidade Federal de Mato Grosso Cuiabá/MT/BR.
} 
Durante nove dias de fevereiro de 2019, uma viagem marcou minha vida como um divisor de águas: antes e depois da Palestina. Antes de chegar na Cisjordânia, passamos por Israel, Aeroporto Ben Gurion, Tel-Aviv. O preparo para chegar lá começou bem antes a fim de conseguir fazer a travessia do Atlântico, passar por Paris e chegar à Palestina: $e$-mails sobre o assunto foram apagados, questionários com perguntas e respostas foram ensaiadas, um medo danado por não saber falar inglês, e o cuidado para não postar nada que pudesse levantar suspeita de ser uma anti-sionista. A ideia superficial era entrar nos territórios sagrados, como turista, mas o destino, de fato, escondemos - eu e minha amiga de viagem. No dia seguinte, saindo de Tel-Aviv, cruzamos a fronteira com um táxi de Israel até Jerusalém antiga e de lá pegamos um ônibus para Belém. O destino era o Campo de Refugiados de Aida, onde ficamos pelos oito dias seguintes e de lá partíamos todos os dias para as visitas guiadas pela cidade e outras da Cisjordânia. Os temas que exploro nos subitens desse artigo foram inspirados nessa experiência empírica na qual pude testemunhar, trocar ideias com pessoas palestinas e a guia brasileira que viveu lá. Escrevo, então, sobre as violências da colonização de Israel na Palestina, a quebra de meus próprios preconceitos com relação ao modo de vestir das mulheres e a alimentação tão rica apesar de todas as restrições consequentes do sionismo. Também pude saber um pouco mais sobre esse centro gravitacional religioso para muçulmanos, judeus e cristãos. Dialogo com alguns autores e fiz pesquisas posteriores na internet para enriquecer o texto.

Escrevo ora no plural porque éramos um grupo de quatro viajantes e uma guia e porque tudo que fiz foi planejado com minha companheira de viagem. Outros momentos escrevo no singular quando digo de particular sentimento sobre as coisas. Meu grupo era formado por uma colega que nem conseguiu entrar na Palestina, foi deportada ao chegar em Israel - parece que desconfiaram dela por ter vindo da Jordânia e antes ter feito trabalhos voluntários no Egito - países onde vivem muitos palestinos. Os demais colegas todos chegaram em Israel, saindo do Brasil, passando pela Europa: eu e Laís de Paris, Aline da Roma, e Marcelo de Amsterdam.

\section{Colonização de Israel na Palestina}

Ao entrar no campo de refugiados de Aida, onde nos hospedamos, passamos pelo portal de entrada representado por uma grande chave, um símbolo, pois, quando os palestinos foram expulsos de suas casas e terras (a partir de 1948 com a criação do Estado de Israel e a intensificação da opressão a partir de 1967), levaram a chave de casa e a esperança de um dia poder voltar. 
Perto desse portal encontramos um grande painel do mártir Aboud Shadi. Pela Cisjordânia vários painéis de palestinos que morreram vitimados pelas ações violentas do exército de Israel estão espalhados em territórios palestinos, mas esse nos chamou especial atenção por se tratar de um menino. Ele foi morto em outubro de 2015. Justo quando estávamos a conhecer a história do jovem, passou por nós o pai dele. Um silêncio se fez e depois nosso guia Baha contou de quem se tratava e chamou atenção para o drama ainda maior de quem tem de reviver a tragédia da perda de um filho todos os dias e ressignificá-la. No painel, além da foto do menino, dizia em inglês e em árabe o seguinte: "Meu nome é Aboud Shadi, um refugiado palestino de 13 anos. Estava aqui mesmo, parado com os meus amigos, quando um sniper israelita me matou com um tiro. A minha alma vai ficar aqui, a perseguir o assassino e a motivar os meus colegas de turma. Questiono-me se a comunidade internacional trará justiça para as crianças palestinas”.

Cerca de um milhão e meio de palestinos vivem na Cisjordânia, território disputado por Israel e pela Palestina desde 1948. Desses, cerca de $70 \%$ dos palestinos vivem como refugiados em seu próprio território. Mais cerca de 7 milhões de palestinos vivem refugiados em outros países, árabes e não árabes.

Parte do que escrevo nesse subitem foi inspirado nas anotações das falas de nossos guias: Fayrouz, da organização Grassroots Al-Quds ${ }^{2}$, e Baha, da to be there ${ }^{3}$.

A criação do Estado de Israel resultou de acordos de reparação aos judeus pós-guerra, em 1948. Antes, a Palestina era um território controlado pelo império britânico, desde 1917. Nessa data, a Carta de Balfour à Federação Sionista da Grã-Bretanha estabelecia o que almejavam como um "Lar Judeu" na Palestina, caso conseguissem derrotar definitivamente o império otomano. Com o fim da $1^{\text {a }}$ Guerra, conseguiram. A carta foi ratificada em 1926 e nos anos seguintes, com o apoio dos Estados Unidos.

Em 1929, os palestinos resistiram - foi a Revolta de Al Buraq, como os árabes chamam o muro das lamentações. Aconteceu ali, na cidade antiga de Jerusalém, onde os rabinos consideravam espaço sagrado para judeus, mas que também o era e é para palestinos, onde fica a mesquita de AlAqsa, que, depois de Meca e Medina, é o terceiro local mais sagrado para os muçulmanos.

Entre 1936 e 1939, houve a segunda revolta palestina quando muitos líderes foram exilados, presos e mortos. E a tensão foi até 1947 quando da criação da ONU (Organização das Nações Unidas)

\footnotetext{
${ }^{2}$ https://grassrootsonline.org/ Acesso em 04 dez 2021.

${ }^{3}$ http://tobe-there.com/ Acesso em $04 \mathrm{dez} 2021$.
} 
e do plano de partilha. Veio a Nakba - a catástrofe - nos anos de 1947 e $1948^{4}$. Foi uma resistência contra o "acordo", uma guerra que expulsou mais de 700 mil palestinos de seus territórios. Uma das estratégias de guerra de Israel era escolher um vilarejo e massacrar quem morava lá com bombardeios, tiros e matança para forçar a expulsão dos palestinos. Então, esses milhares foram, inicialmente, para a Jordânia, Síria, Líbano ou Gaza. Foram 514 vilarejos destruídos. Na narrativa de Israel, era uma nação lutando contra três países. Para Illan Pappé ${ }^{5}$, historiador judeu revisionista ${ }^{6}$, era parte do projeto de limpeza étnica.

Em 1967, houve um acirramento do conflito. Aconteceu a "Guerra dos Seis Dias", que resultou, entre tanta destruição, na ocupação da parte oriental da Palestina e de Jerusalém. As colônias judaicas se estabeleceram também em território palestino, a exemplo da Hebrom ocupada. Os palestinos que permaneceram em Jerusalém ganharam status de "residentes permanentes". A carteira de permanência, no entanto, precisa ser renovada de tempos em tempos e as pessoas que a possuem precisam prestar juramento a Israel e dizer "Jerusalém é o centro da vida". Entre as exigências estabelecidas para um "residente permanente" consta o compromisso de não estabelecer conexão com outras cidades - isso implica perder contato com parentes e não poder se casar com pessoas de fora.

Hebrom é um retrato catastrófico do poder colonial de Israel, pois, nesse território, os palestinos são obrigados a conviver com as colônias israelenses estabelecidas em meio a eles. Israel não autoriza que os palestinos residentes da área H2 (controlada pelo exército) tenham carro nem que andem pelas ruas interditadas, obrigando palestinos a darem grandes voltas por caminhos hostis, porque, como dividem passagens com judeus sionistas, estão sujeitos a humilhações, pedradas, quando não são mortos.

Em 1967, Israel implantou o plano "master" de expansão. Então, as colônias que foram se estabelecendo eram de vários tipos. As colônias independentes são espécie de condomínios fechados com toda estrutura e até encanamentos independentes levando água que nunca falta, enquanto nos campos de refugiados o abastecimento é controlado. Não é todo dia que chega água e, quando chega, precisam fazer reserva. Então, uma maneira de reconhecer e diferenciar o que é colônia e o que é um campo de refugiados é observar se no teto tem os reservatórios pretos.

\footnotetext{
${ }^{4}$ Sobre esse tema, sugiro o livro de Soraya Misleh. Al Nakba: um estudo sobre a catástrofe palestina. São Paulo: Ed. Sundermann, 2017.

${ }^{5}$ Illan Pappé. A limpeza étnica da Palestina. São Paulo: Ed. Saudermann, 2016.

${ }^{6}$ Estou a considerar revisionista os historiadores que criticam a narrativa romântica e redentora do Estado de Israel, e têm, por meio de suas pesquisas e publicações, denunciado as atrocidades e o genocídio consequente do sionismo, ao arrepio das autoridades governamentais de suas nações de origem.
} 
Existem os bairros-colônias fora da linha verde. E as colônias dentro dos territórios palestinos, como citei o exemplo de Hebrom. Há, ainda, as colônias com "vista sionista" de onde não se vê os palestinos, graças ao muro "da exclusão" e a localização privilegiada; também os transportes são exclusivos para judeus.

\section{Pontos de controle e violência}

No sétimo dia pela Palestina, foi dia de visitar a Esplanada das Mesquitas e a cidade antiga de Jerusalém. Roteiro turístico comum aos visitantes da região - religiosos cristãos, judeus e muçulmanos - sonho de todos esses mais praticantes. Todavia, só aos palestinos é imputado o caminho do martírio para se chegar lá, pois só podem ir a Jerusalém com autorização de Israel. Se moram em Jerusalém, precisam ter a carteira de "permanência" (que não é permanente, como já foi dito). Os que conseguem uma autorização temporária para trabalhar ou fazer consulta médica e exames precisam passar pelo check-point.

Os check-points estão em vários locais estratégicos, passamos por alguns de carro, que é mais tranquilo porque a revista é aleatória. Para turistas, normalmente mandam passar depois de fazer algumas perguntas objetivando a certificação de que somos mesmo turistas. Fazer fotos nesses lugares é arriscado porque as guaritas têm uma visão panorâmica e são cheias de guardas armados.

Bom lembrar a particularidade do serviço militar em Israel: é obrigatório a partir dos 18 anos para homens (por 3 anos) e mulheres (por 2 anos), e existe ainda o recrutamento de voluntários, feito a partir dos 15 anos de idade, dentre os quais a maioria vem dos Estados Unidos, dispostos a morrer e matar por Israel. Então, o que vemos são pessoas muito jovens com um fuzil nas mãos e com um poder imenso que a arma lhes confere. Dentre esse contingente bélico, um sexto das mulheres sofre assédio sexual e cerca da metade da população LGBT também - deve ser mais, porque a maioria não tem coragem de falar ou denunciar ${ }^{7}$.

Os palestinos também podem engrossar as fileiras do exército de Israel. Parece uma contradição, mas, para eles, é uma oportunidade de emprego e de ter algum poder. Todavia, como todos que trabalham para Israel, prestam juramento de lealdade. Um soldado palestino recrutado por Israel não pode nunca ajudar um cidadão palestino - o máximo que ele pode fazer é tentar não fazer nada. Ou seja, se ele conseguir não ferir, não prender ou não matar um compatriota, já estará a fazer algo pela

\footnotetext{
${ }^{7}$ Ver https://www.monitordooriente.com/20210216-acusacoes-de-assedio-sexual-no-exercito-de-israel-aumentam-em24/ Acesso em 16 fev 2021.
} 
Palestina. Claro que por isso pode ser julgado por omissão, preso, expulso da corporação e perder seus “privilégios”.

Para os palestinos, se colocar contra o Estado de Israel é uma luta, minimamente, desigual. Eles não podem portar armas, principalmente depois de assinado o armistício por meio do "Acordo de Oslo”, em 1993, entre as então autoridades máximas de Israel (Isaac Rabin, primeiro-ministro e o presidente Shimon Peres) e Palestina (Yasser Arafat). Em 1994, como consequência desse acordo, Rabin, Peres e Arafat receberam o Prêmio Nobel da Paz, mas as resistências judaicas, sobretudo ortodoxas, foram intensas e Rabin foi assassinado no ano seguinte. O plano de Oslo consistia em vários pontos que nunca foram cumpridos, só a primeira etapa se efetivou: a retirada israelense da Faixa de Gaza, onde o Hamas - único braço armado das forças palestinas -, pôde expandir seu poder, principalmente desde 2006 quando conseguiu maioria no parlamento fazendo oposição ao Fatah que é o partido do atual representante palestino, Mahmoud Abbas. Mas um representante de um Estado fragilizado, sem exército e sem armas, fica desacreditado pelos seus compatriotas, também pela sua postura figurativa e de alianças pouco confiáveis.

Quando visitamos Ramallah, considerada a Paris Palestina, e o Mausoléu de Arafat, percebemos a pouca importância que a população dá ao seu presidente. Um enorme e super cuidado Mausoléu e na frente uma faixa do governo destroçada.

A caminho de Ramallah, ao sair de Jerusalém, fomos abordados no ônibus pela polícia de Israel, que entrou para conferir os documentos de todos. Ali ninguém foi preso nem retirado do ônibus. Um palestino que estava na nossa frente, acompanhado de um parente que morava fora (parecia que eles se reencontravam depois de décadas), conseguiu driblar a fiscalização com um argumento duvidoso, porque poucas vezes vimos complacência aos argumentos palestinos. O palestino abordado disse ter mais de 65 anos e que, por isso, não precisava da autorização, apresentava só a identidade.

A gente presenciou algumas violências de judeus contra palestinos, não só por parte da polícia e dos soldados. Os guias muitas vezes indicam aos turistas que não comprem nos comércios árabes, insuflando o ódio contra supostos "terroristas".

Existe a violência da ocupação, mas também a que é feita em grande estilo em Jerusalém. Exemplos estão no tipo de arquitetura ocupada, como a casa que fora de um dentista palestino e que reserva ainda no muro a placa indicando seu nome e sua profissão. Ele morava e fazia seu exercício de odontologia, mas sua casa foi tomada pelos israelenses e ocupada. A ocupação obriga a maioria dos palestinos que resistem à vida nos campos de refugiados. Ou seja, são refugiados dentro do seu próprio território. 
Tem a violência dos muros, também, que, para Israel, foi construído para criar "áreas de segurança" (para quem?), mas os palestinos chamam de muro da anexação ou da confiscação, porque é mais uma forma de restringir e limitar os palestinos.

Os soldados fazem revistas humilhantes aos palestinos para conferir se não carregam armas ou objetos considerados suspeitos.

Imagina um trabalhador, como vimos, passando pelo corredor do check-point $^{8}$ palestino (de Belém para Jerusalém) carregando uma maleta de ferramentas para a construção civil, quão perigoso pode parecer. Foi difícil a travessia por esse corredor, de número 300. Levou mais ou menos uma hora. Mas os trabalhadores podem levar até três horas, pois muitos chegam lá às $4 \mathrm{~h}$ da madrugada para conseguir chegar em tempo nos seus compromissos em Jerusalém. Ao lado desse corredor, tem outro para pessoas idosas, enfermas ou mulheres com crianças e pessoas com necessidades especiais, mas não raro essas pessoas vão até o fim do corredor gradeado e ficam gritando para que os soldados abram o portão. Mendigando misericórdia de quem parece ter prazer de ver o suplício de gente indefesa, que consideram inimiga. Voltam para passar em meio ao corredor "dos homens" que vão abrindo caminho para esses em piores condições.

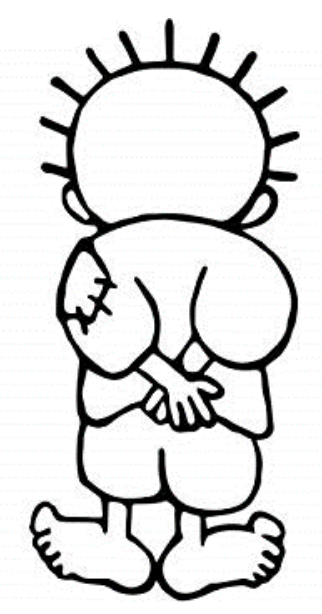

Handala é uma representação do menino refugiado palestino criado pelo cartunista palestino Naji al-Ali, entre 1979-80. Esse desenho em grafite esteve presente em vários lugares por onde passamos. O menino palestino é representado de costas. E o artista dizia que quando a Palestina e o menino fossem livres, ele mostraria o rosto, mas isso nunca aconteceu. Em 1987, Naji foi assassinado.

$\mathrm{Na}$ Palestina, toda família tem alguém que foi ou está preso pelas autoridades israelenses. Israel aprisionou cerca de $40 \%$ da população palestina masculina. Uma coisa que está ao alcance de

\footnotetext{
${ }^{8}$ Sobre esse check-point, podem também ver: https://www.youtube.com/watch?v=V3b0NVBsPDQ A equipe que produziu esse vídeo "Bethlehem checkpoint, 4am" contou com a participação da esposa da nossa guia, a fotojornalista Anne Paq. Ele tem versão de subtítulos em inglês e em francês.
} 
todos nós, contra as atrocidades cometidas por Israel, é apoiar o BDS (Boicote, Desinvestimentos e Sanções). O BDS é um movimento que fomenta a retaliação cultural, acadêmica e econômica com fins de diminuir o poder de Israel, visa também ampliar o apoio internacional a pressionar Israel a respeitar o direito internacional ${ }^{9}$.

Existem judeus, não sionistas, que contestam as ocupações de Israel nos territórios palestinos. Lizzie Doron, no seu último livro publicado em 2017, "Sweet occupation", é um exemplo. Outra referência é Nurit Peled-Elhanan ${ }^{10}$. Nurit Peled é filha de Mattityyahu Peled, um general do exército de Israel que foi beneficiado pela ocupação. A família, ao entrar na casa onde os palestinos haviam recém sido expulsos, encontrou até o café quente servido. Esse fato marcou emocionalmente essa família e, posteriormente, teria corroborado para o suicídio da irmã de Peled. Nurit se tornou uma militante pacifista e professora de Literatura Comparada da Universidade Hebraica, além de uma das fundadoras da associação Bereaved Families for Peace.

\section{A alimentação}

Um quilo de carne para os palestinos custava na ocasião (fevereiro de 2019) cerca de $\mathrm{R} \$ 100,00$ (cem reais), valor impraticável para eles. Devido às condições limitadas dos campos de refugiados, também não existe espaço para criação de animais, sobretudo de grande porte. Alguns frangos são criados em confinamento - o que só aumentava a aversão do meu grupo de viajantes sobre a procedência dessas carnes. Essas situações que envolvem violências contra animais e humanos me fizeram pensar sobre os processos de expansão do agronegócio no Brasil que resultaram no desmatamento das florestas e do cerrado, provocaram o desequilíbrio de ecossistemas como no Pantanal mato-grossense para criação de gado bovino e grandes monoculturas agrícolas, além de terem atingido diretamente populações indígenas. Enfim, me decidi não mais comer carne vermelha por todas essas implicações políticas envolvidas, sobretudo, considerando o poder destrutivo do agronegócio na região onde moro (centro-oeste).

Antes da Palestina, eu tinha certo preconceito com comida árabe. Dizia não gostar porque julgava ter sempre muita cebola. Gostava de quibe, desde que não fosse recheado de cebola, como uma vez me foi servido em um restaurante árabe de São Paulo. Mas, de fato, eu conhecia muito pouco dessa gastronomia, por isso tantos preconceitos. Quando estivemos em Nablus, ao experimentar o

\footnotetext{
${ }^{9}$ Ver mais em: https://bdsmovement.net/pt. Acesso em 04 dez. 2021.

${ }^{10}$ Nurit Peled-Elhanant. Ideologia e Propaganda na Educação: a Palestina nos livros didáticos israelenses. (São Paulo: Ed.UNIFESP; Boitempo, 2019).
} 
que estava a ser apresentado como uma iguaria local, uma espécie de esfirra de espinafre e cebola, e recusar depois da primeira mordida por causa do sabor marcante da cebola, me denunciaram à anfitriã Fátima, ela me olhou e disse: “perdeu metade da vida”. Então, tenho feito um exercício de recuperar uma parte da vida perdida e me reconciliar com esse ingrediente.

Nossa guia de viagem à Palestina é vegana e faz do veganismo uma política de e pela vida mesmo. Eu a conheci em 2012, por meio do blog dela ${ }^{11}$ recomendado por minha parceira de viagem, Laís. O blog nos fez viajar pela Palestina sem ainda a conhecer. Comer ou falar de comida alimenta o corpo e a alma de sentidos. E os sentidos são políticos. O motivo pelo qual os palestinos refugiados não comem carne não é tanto por ativismo vegano, é por não ter condições de levar à mesa um alimento que é deveras dispendioso para eles. Afinal, a vida nos campos de refugiados em áreas limitadas e controladas pelo Estado de Israel impede os palestinos de expandir negócios e cultivo agrícola, ainda que para consumo próprio.

Sobre a arte das padarias, é importante destacar o manakish za'tar uma massinha de trigo assada com azeite e za'tar. Comemos um delicioso preparado pelo padeiro de Nablus - inesquecível. $\mathrm{Na}$ entrada da padaria de Nablus, nossa guia Fátima explicou o que significava os dizeres em árabe na porta: "Não tem produto de Israel". Ela falava com o orgulho da resistência. Nos sentimos orgulhosos também. Das lembranças gostosas de Nablus, ficou o grande bolo de rua, o knafel que nos fez comer alimento de origem animal pela primeira e única vez durante nossa estada na Palestina, pois é recheado com queijo de cabra. Simples bolo de semolina, regado com calda doce, assado e acompanhado desse queijo salgado produzido pelos palestinos beduínos.

Uma das coisas que não faltava diariamente à nossa mesa palestina era o hummus. E a gente repetia com nossa guia: hummus é vida. Essa pastinha é $90 \%$ grão de bico e o restante é toque de tahine (pasta de gergelim), limão, alho e sal. Normalmente o hummus se come com o pão árabe (para nós o que mais se aproxima é o que chamamos de sírio). Na casa de Dragica, outra anfitriã nossa, o hummus veio acompanhado de graça na apresentação. Ela ficou o dia inteiro preparando comidas maravilhosas, boa parte dos ingredientes foram colhidos nas hortas cultivadas por ela no pequeno quintal e no terraço da casa - um ato de resistência em território controlado. Tinham pimentões defumados e adocicados, favas, azeitonas, couve-flor empanada ( $m c h a t)$, pastinha de berinjela com tahine e muita salsinha - enfim, só carinho e delícias!

$\mathrm{O}$ aroma das especiarias ficou como das lembranças mais marcantes da viagem. Tawfic, na sua loja de especiarias, em Belém, nos trouxe azeite feito por ele, vinagre de romã, za 'tar, e outros

\footnotetext{
${ }^{11}$ http://www.papacapim.org/ Acesso em 4 dez. 2021.
} 
tantos temperos combinados. Ele contou o segredo do que ouvíamos em todas as lojas que adentrávamos e nos ofereciam café dizendo que ali se fazia o melhor café do mundo. Já estava a pensar que estavam tirando sarro da nossa cara. Até que ele pediu que o ajudante da loja trouxesse da dispensa o saco do café. Ao erguê-lo, estava escrito "Made in Minas Gerais". Até hoje me emociono com esse episódio. Na verdade, eles queriam dizer todo tempo que o melhor café do mundo é o brasileiro.

De volta ao Brasil, tenho reproduzido muito do que aprendi sobre a saudável cozinha árabe. Nos encontros, acabo por contagiar as pessoas com meus preparos de hummus, mutabal e sobretudo o tabule, que quero fazer todas as pessoas experimentar, sempre reforçando que é palestino, não libanês como se conhece no Brasil. Para ajudar a difundir a culinária palestina, trouxe de lá um livro de receitas que Sandra organizou com Islam ${ }^{12}$. A aquisição do livro era também uma forma de reverter recursos para a associação Noor $^{13}$ (luz, em árabe), fundada por Islam junto com outras mulheres que têm filhos com deficiências. Um dos pratos que reproduzi algumas vezes é a maqluba. O prato é semelhante a um cozido de legumes, arroz e várias especiarias que o deixam saborosíssimo. Nos hábitos deles, serve-se o prato no centro da mesa e todos vão comendo às colheradas direto do prato principal. Outro prato principal que preparamos foi a mujaddara. Uma espécie de risoto com lentilha, macarrão fino frito e cebola caramelizada por cima.

Ainda tento me reconciliar com a cebola, mas também aprendi que nem toda comida árabe é acebolada, como pensava antes. Passei a amar a comida árabe-palestina.

\section{O uso do véu}

Às vésperas de ir embora da Palestina comprei um véu no mercado de Jerusalém por vinte shekels. Pedi que Islam me ensinasse a usá-lo e ela me deu várias demonstrações de formas e usos, exemplificando em minha cabeça. São várias as maneiras como se pode prender na cabeça, em geral com auxílio de alguns alfinetes, e acrescentar graça ao acessório.

Perguntei a ela se era ofensivo a eles a minha iniciativa de querer aprender como usar o véu, já que eu não sou muçulmana e não estava a fazer nenhuma conversão religiosa. Ela e o marido Ahmad, que presenciava a cena, responderam em uníssono que não, sentiam-se lisonjeados pela minha iniciativa de querer conhecer mais a cultura deles.

\footnotetext{
${ }^{12} \mathrm{O}$ título do livro é "Zaaki", significa "gostoso" em Árabe. O título completo do livro em Português é: Zaaki-Receitas palestinas saborosas direto da nossa cozinha no campo de refugiados de Aida. Em inglês: Zaaki: tasty palestine recipes from our kitchen in Aida Refugee Camp. Bethlehem, Palestine. 2015.

${ }^{13}$ https://www.youtube.com/watch?v=Q8aKZSTHUHc . Acesso em 30/09/2021.
} 
Grosso modo, o véu deve cobrir a cabeça e todo o cabelo. Algumas usam uma toquinha por baixo para não aparecer nada (como seria recomendado nesse véu que adquiri por causa da transparência), ou uma tiara que cobre parte da testa. Em geral, as mulheres ficam sem o véu em casa e só a família (filhos e marido) veem os cabelos das mulheres adultas e casadas. Existe um certo charme e ar de mistério em tudo isso. E, claro, pelo tipo de véu que se usa ou como se usa é possível distinguir a casada da solteira ou a condição social. Então, o véu é, também, um sinal de distinção social e de pertencimento.

Muitas moças usam roupas ocidentalizadas, calças (em geral, não coladas), por exemplo, mas não deixam de usar o véu. O vídeo citado na nota 13 mostra várias mulheres (Islam também aparece) e é possível visualizar diversos usos do véu.

Islam, nossa principal anfitriã porque ficamos hospedados na casa dela, tem um filho que nasceu com paralisia cerebral. Ele já é adulto, mas ela encabeçou e criou a associação Noor, inicialmente na própria casa, junto com outras mulheres, para se ajudarem mutuamente no tratamento e reabilitação de crianças com deficiências. Se a vida no campo de refugiados é difícil, mais ainda para pessoas com deficiências e para as famílias delas, pois as condições de mobilidade ficam bastante comprometidas. No referido vídeo, Islam diz que respeita os homens, mas quem se ocupa das crianças 24h são as mães. Verdade para a realidade que conhecemos e não muito diferente em outras culturas, mesmo as que se dizem modernas. Islam se casou muito nova, aos dezesseis anos, teve seis filhos, perdeu um irmão, um cunhado e uma cunhada por causa da ocupação e o marido ficou preso, na cadeia israelense, durante vários anos. Hoje ele está em casa, mas, por causa da tortura sofrida na prisão, carrega sequelas físicas que o impedem de exercer sua profissão de eletricista. Islam teve de reconstruir com o marido a sua casa, que foi atacada e bombardeada pelos soldados de Israel quando os filhos eram pequenos e os dois últimos nem nascidos. Ela resistiu, gritou e implorou para poder salvar seu filho deficiente dos escombros, até que um soldado se apiedou e o trouxe para ela. Islam é uma mulher muito forte. Emociona-me falar dela.

Entre as mulheres da "Casa da Dignidade" (Beit Al-Karama), em Nablus, Aya e Fátima foram as que nos acompanharam em visita à cidade. Elas nos deram exemplos de que não há uma regra para as mulheres muçulmanas, não há obrigatoriedade de usar o véu. As que optam por não usar, como Aya e Fayrouz (de Jerusalém), têm de passar pelo incômodo de dar mais explicações do porquê não o usam. 
Zleikha, nossa guia de Hebrom, também usa o véu. Divorciada, ela vive com a mãe e, na casa delas, funciona uma escolinha infantil o que as tornam pessoas muito respeitadas e reconhecidas na comunidade também.

Dragica, a bordadeira bósnia que se casou com um palestino, converteu-se ao islamismo. Ela e o então marido se conheceram estudantes na Bósnia, nos anos 90. Na época, as coisas estavam ruins por lá e ela decidiu ir com ele para a Palestina. Logo as coisas pioraram na Palestina e ela ficou 14 anos sem documento palestino - o que a impediu de poder visitar seus pais na Bósnia todo esse tempo (ela é filha única). Dragica criou uma associação de bordadeiras e tudo que vendem reverte para as mulheres da associação. Ela é muito sagaz, aprendeu inglês estudando em casa e vendo programas de TV, além de excelente cozinheira, como mencionei.

Todas as mulheres eram protagonistas. Com véu ou sem, não vi submissão e apagamento nelas. Ao contrário, brilho e força incríveis. Senti-me profundamente tocada por todas, por suas situações específicas de dificuldades e de perdas. Senti-me fortalecida na força delas, na dignidade comovente que elas imprimem nos seus trabalhos e ações.

O véu é uma expressão cultural e religiosa que pode dizer de uma suposta submissão inscrita no Corão imposta só às mulheres, mas é sempre possível dizer não. O véu pode ser uma forma de apagamento também. Uma mulher que usa o véu está, talvez, mais protegida de abusos. Observamos que os homens não tocam nas mulheres se não houver uma relação de permissividade e intimidade previamente estabelecida. O véu pode ainda ser libertador quando imposto pelos pais como uma condição para a filha ir para outra cidade estudar, por exemplo.

São muitas as facetas do uso do véu. Não cabe a nós julgar para não cairmos no erro do orientalismo tão denunciado por Edward Said ${ }^{14}$, quando fala que costumamos olhar para o oriente com as lentes ocidentais. $\mathrm{O}$ que vi foram muitas mulheres diferentes. $\mathrm{O}$ véu as une culturalmente, é uma marca de pertencimento. Com ou sem o véu, o mais importante foram os ensinamentos de força e sororidade.

\section{O cristianismo em meio a cultura judaica e muçulmana}

Devo dizer que Jesus nos safou das desculpas para poder entrar na Palestina e driblar a segurança policial de Israel. Afinal, o pretexto era visitar a cidade sagrada. Fui buscar meu apoio no meu catolicismo apreendido (não sou católica praticante, mas foi nessa religião que me criei e segui muitos

\footnotetext{
${ }^{14}$ Edward Said. Orientalismo: o oriente como invenção do ocidente. (São Paulo: Companhia das Letras, 2007).
} 
de seus sacramentos e doutrinas - coisas que marcam um modo de ser e agir sobre as coisas). Íamos conhecer onde Jesus nasceu, o lugar por onde ele pregou, passou, viveu e morreu. Ele viveu ali, com os fariseus, samaritanos - todos semitas - árabes e hebreus, de religiões monoteístas, cuja árvore era a mesma, dos patriarcas Abraão, Isaac e Jacó.

Em Hebrom, está o túmulo dos patriarcas, a Mesquita de Ibrahim (nome muçulmano de Abraão) local sagrado para judeus e muçulmanos. A mesquita está dividida em duas partes - uma para os muçulmanos e outra para os judeus (sinagoga) -, desde o massacre de vinte e nove palestinos ali dentro, na hora do salá ${ }^{15}$ por um colono judeu de origem estadunidense, em 25 de fevereiro de 1994. Desde então, os judeus podem visitar o túmulo dos patriarcas somente dez dias por ano. O púlpito foi construído em 1091 para uma mesquita em Ascalon e doado por Saladino em 1191, sobrevivendo aos ataques dos cruzados. Só três desses púlpitos árabes existem ainda no mundo Zleikha mostrou o monumento ricamente ornado. As mesquitas têm sido alvo de ataques extremistas. Em 15 de março de 2019, na Nova Zelândia, um fascista australiano assassinou cinquenta pessoas na Mesquita de Noor, a grande maioria eram homens.

Os muçulmanos adultos praticantes devem rezar em público cinco vezes por dia, em direção à Meca. Não é necessário que todas as orações sejam na mesquita. Entretanto, durante o Ramadã, sim, as mesquitas são muito frequentadas. A data do Ramadã varia a cada ano, conforme o calendário árabe. Em 2019, foi entre 6 de maio e 4 de junho. Durante o mês sagrado do Islã, os muçulmanos praticam jejum durante o dia até o pôr-do-sol.

Nas mesquitas, homens e mulheres ocupam lugares e posições diferentes. Em geral, elas ficam atrás dos homens ou mesmo não vão, podem orar em casa. Algumas correntes do Islã são menos ou mais rigorosas quanto a presença de mulheres nas mesquitas. Não podem nunca entrar sem cobrir a cabeça.

Pelas ruas da Jerusalém antiga, também passou Jesus pelo seu caminho até a crucificação. Entre os comércios, passamos pelas vias sacras, porque é onde Jesus cumpriu seu suplício.

Ainda na Jerusalém antiga, visitamos o Santo Sepulcro. O sepulcro mesmo é vazio, mas não importa, as pessoas fazem filas para confirmar que Jesus não está mais lá, ou está. O templo do Santo Sepulcro também é dividido entre católicos e a ostentação dos ortodoxos.

\footnotetext{
${ }^{15}$ O Salá é o momento das orações. Fazem chamadas pelos alto-falantes avisando a hora da reza nas mesquitas. São cinco vezes de oração que os muçulmanos devem realizar diariamente.
} 
Antes do suplício, Jesus esteve a se preparar pelo deserto de pedras de Jericó. E, no "monte das tentações", se ergueu um mosteiro encravado nas rochas, onde hoje se pode subir de bondinho e comer em refinado restaurante.

Contudo, Jesus nasceu pobre e onde? Na Palestina, terra de São Jorge também, de gente guerreira. Dizem que em uma manjedoura, onde hoje tem uma basílica e, dentro da igreja, um marco do santo nascimento. Belém, então, fica na Palestina, embora Israel coloque seus poderes militares por lá. A Palestina é árabe e deve ser livre.

\section{Considerações}

Sabíamos muito pouco antes de viajar à Palestina. Não dimensionávamos o que é viver numa prisão a céu aberto como é um campo de refugiados, onde as pessoas que ali vivem, advindas de seus vilarejos originários, precisam passar por privação de necessidades básicas como liberdade de locomoção e até de abastecimento de água. Sem falar nas restrições alimentares impostas por Israel aos palestinos devido a limitação das áreas chamadas de campos, mas sem terreno próprio para plantação ou criação de animais. Até as centenárias oliveiras são confiscadas, quando não derrubadas ou queimadas, para mostrar quem manda nos territórios ocupados.

Sobre resistência foi a lição que mais aprendemos junto aos palestinos. Cada casa que visitamos, ruas que passamos, portões e grades que também atravessamos vimos os rostos de dignidade desse povo árabe. Talvez esse seja o terror que provocam: a existência digna.

Não é justo que os palestinos sejam expiados pelos crimes cometidos pelos nazistas contra os judeus. Como disse Edward Said: "os palestinos não devem mais ser submetidos a essas provocações, é um ato de cumplicidade e covardia moral de dimensão singular". E acentua: "Nenhum outro movimento na história teve um oponente tão difícil: um povo reconhecido como vítima clássica da história"16.

\section{Referências:}

Misleh, Soraya. Al Nakba: um estudo sobre a catástrofe palestina. São Paulo: Ed. Sundermann, 2017.

\footnotetext{
${ }^{16}$ Edward Said. A questão palestina. São Paulo: EdUNESP, 2012. p. XXXIV.
} 
Pappé, Ilan. A limpeza étnica da Palestina. São Paulo: Ed. Sundermann, 2016.

Peled-Elhanan, Nurit. Ideologia e Propaganda na Educação: a Palestina nos livros didáticos israelenses. São Paulo: Ed.UNIFESP; Boitempo, 2019.

Said, Edward W. Orientalismo: o oriente como invenção do ocidente. São Paulo: Companhia das Letras, 2007.

Said, E.W. A questão palestina. São Paulo: EdUNESP, 2012. 